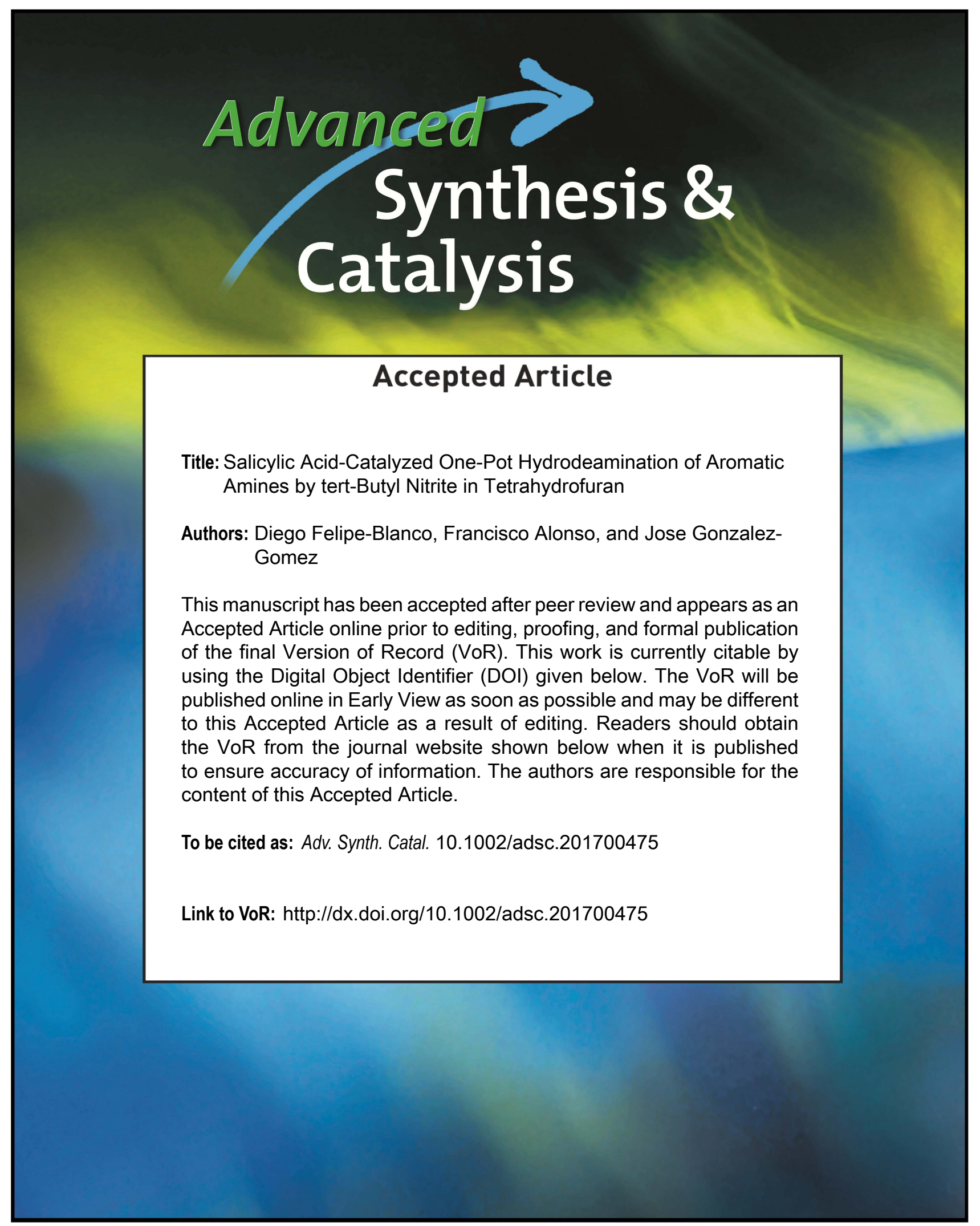


DOI: 10.1002/adsc.201((will be filled in by the editorial staff))

\title{
Salicylic Acid-Catalyzed One-Pot Hydrodeamination of Aromatic Amines by tert-Butyl Nitrite in Tetrahydrofuran
}

\author{
Diego Felipe-Blanco, ${ }^{\mathrm{a}}$ Francisco Alonso, ${ }^{\mathrm{a}}$ and Jose C. Gonzalez-Gomez ${ }^{\mathrm{a}, *}$ \\ a Instituto de Síntesis Orgánica (ISO) and Departamento de Química Orgánica, Facultad de Ciencias, Universidad de \\ Alicante, Apdo. 99, 03080 Alicante, Spain. \\ E-mail: josecarlos.gonzalez@ua.es
}

Received: ((will be filled in by the editorial staff))

Supporting information for this article is available on the WWW under http://dx.doi.org/10.1002/adsc.201\#\#\#\#\#.((Please delete if not appropriate))

\begin{abstract}
A significant acceleration in the hydrodeamination of in situ formed diazonium salts (from aromatic amines) has been observed in the presence of 10mol\% salicylic acid, using tetrahydrofuran as the hydrogen donor. The reaction proceeds efficiently at $20^{\circ} \mathrm{C}$ for a wide range of substituted anilines, even at 10 -mmol scale, without any other additive. The same protocol has been adapted to the selective deuterodeamination of some aromatic amines. Control experiments clearly show that aryl radicals are involved in the reaction mechanism.
\end{abstract}

Keywords: hydrogen transfer; radicals; aromatic amines; isotopic labelling; sustainable chemistry

\section{Introduction}

Anilines are highly activated substrates for electrophilic aromatic substitutions, and the subsequent removal of the amino group is a wellknown strategy to exploit its activating and directing effect in the synthesis of aromatic compounds. Typically, this transformation is achieved by the initial formation of the corresponding arenediazonium salt, followed by a hydrodediazotization. A plethora of reductive protocols have been implemented with this purpose, ${ }^{[1]}$ involving different hydrogen donors, namely: alcohols, ${ }^{[2]} \mathrm{HPO}_{3},{ }^{[3]} \mathrm{NO} / \mathrm{THF},{ }^{[4]} \mathrm{Et}_{3} \mathrm{~N}^{[5]}$ catalytic $\mathrm{Fe}(\mathrm{II})$ in DMF, ${ }^{[6]}$ and trichlorosilane. ${ }^{[7]}$ Recently, a visible-light promoted reaction catalyzed by Eosin B in DMF has also been reported. ${ }^{[8]}$ One common drawback in most of the existing methods is that they rely on the isolation of unstable aryl diazonium salts. In this context, a more limited number of one-pot procedures have been developed, including: (a) the use of $\mathrm{NaNO}_{2}$ in $\mathrm{H}_{3} \mathrm{PO}_{2},{ }^{[9]}$ (b) the reaction with alkyl nitrites in $\mathrm{THF}^{[10]}$ or $\mathrm{DMF}^{[11]}$ at $65^{\circ} \mathrm{C}$, (c) $\mathrm{NaNO}_{2}$ in AcOH/ $/ \mathrm{H}_{2} \mathrm{O}$ followed by $\mathrm{NaHSO}_{3},{ }^{[12]}$ and recently, $\mathrm{NaNO}_{2} / \mathrm{AcOH}$ in $\mathrm{CHCl}_{3} / \mathrm{H}_{2} \mathrm{O} .{ }^{[13]}$ Importantly, the use of a deuteride equivalent as the hydrogen source would give access to regioselectively deuterated aromatic compounds. The latter compounds play important roles in the elucidation of reaction mechanisms, ${ }^{[14]}$ as well as in the investigation of biosynthetic pathways. ${ }^{[15]}$

Some of the above mentioned methods require water or alcohols to solubilize $\mathrm{NaNO}_{2}$, the reaction of which with the intermediate diazonium salt gives rise to undesirable phenols or ethers. In addition, the low solubility of inorganic salts in organic solvents is usually overcome with the use of a large excess of reagents and solvents, which clearly reduces the feasibility of the protocol. It is also worth noting that electron-donating groups significantly retard the reaction and many of the developed methods fail for this subclass of substrates. ${ }^{[4]}$ In principle, we found the use of alkyl nitrites in organic solvents attractive because some of the aforementioned limitations can be minimized. In this regard, the only one-pot procedures described make use of $\mathrm{DMF}^{[11]}$ or $\mathrm{THF}^{[10]}$ at $65^{\circ} \mathrm{C}$ (Scheme 1a and 1b). Given the commercial availability of $\left[\mathrm{D}_{8}\right]-\mathrm{THF}$ and its lower toxicity compared to $\mathrm{DMF}{ }^{[16]}$ we reasoned that the use of alkyl nitrites in $\mathrm{THF}$ at $20-25{ }^{\circ} \mathrm{C}$, under almost neutral conditions, would be a more convenient protocol for the reductive deamination of anilines (Scheme 1c).

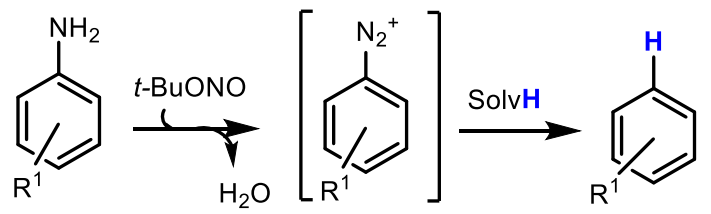
a) boiling THF [ref. 10]
b) DMF $65^{\circ} \mathrm{C}$ [ref. 11]
c) THF, $20^{\circ} \mathrm{C}$, salicylic acid (10 mol-\%) [this work]

Scheme 1. One-pot procedures in anhydrous media for the hydrodeamination of anilines. 
Recently, Carrillo and co-workers demonstrated that in-situ generated arenediazonium ions can be conveniently reduced to aryl radicals at room temperature, using substoichiometric amounts of ascorbic acid $\left(\mathrm{AscH}_{2}\right)^{[17]}$ or gallic $\operatorname{acid}^{[18]}$ as promoters. The $\mathrm{AscH}_{2}$ protocol has been implemented for the radical $\mathrm{C}-\mathrm{H}$ arylation of (hetero)arenes in the preparation of aryl sulfides, ${ }^{[19]}$ in a $[4+2]$ benzannulation to build phenanthrenes, ${ }^{[20]}$ and in a radical translocation to form $\alpha$ alkoxybenzamides. ${ }^{[21]}$ However, to our surprise, the use of these promoters in a one-pot reductive deamination of anilines has not been documented so far.

\section{Results and Discussion}

Considering the lower reactivity of electron-rich substrates in the title reaction, we selected $p$-anisidine as a model substrate to carry out the reductive deamination, via diazonium salt, in the presence of different possible promoters and THF at $20^{\circ} \mathrm{C}$ (Table 1). The reaction worked poorly in the absence of additives at $20^{\circ} \mathrm{C}$ and a moderate yield was obtained at $65{ }^{\circ} \mathrm{C}$ (entry 1 ), probably through in-situ formed diazo anhydrides (Ar-N=N-O-N=N-Ar) and their radical fragmentation. ${ }^{[22]}$ However, the addition of 10 mol-\% of ascorbic acid, gallic acid, or salicylic acid (entries 2, 6 and 7) significantly enhanced the reaction, leading to anisole in excellent yield after $3 \mathrm{~h}$ of reaction. Additives such as (+)-CSA (camphorsulfonic acid) or DMSO (dimethyl sulfoxide) had a moderate positive impact on the reaction. We have not found any precedent in the literature for the use of salicylic acid to promote the generation aryl radicals. Thus, we focused our attention on this catalyst because: (a) it is inexpensive (59€/1 Kg, Sigma-Aldrich); (b) it is non-toxic in low doses (an active metabolite of aspirin); and (c) it is a renewable feedstock (a plant hormone derived from salicin). It is known that household compact fluorescent lamps (CFL >360 $\mathrm{nm}$ ) allow the generation of aryl radicals from aryldiazonium salts under catalyst free conditions. ${ }^{[23]}$ For this reason, we confirmed that a quantitative yield was also obtained when the mixture of our model reaction was protected from light (entry 8). Interestingly, both hydroxyl groups need to be free in the promoter in order to maximize the yield. For instance, the addition of methyl salicylate (entry 9) had no effect on the background reaction (entry 1) and a poor acceleration was observed in the presence of O-acetyl salicylic acid (entry 10).

With the optimized conditions in hand, we next explored the scope and limitations of the developed protocol with different anilines (Table 2). We screened diverse substituted anilines with electrondonating and electron-withdrawing groups. The products were obtained in synthetically useful yields regardless the electronic nature of the substituent, ranging from moderate to excellent. Giving the mild conditions used, a variety of substituents and
Table 1. Optimization of the reaction conditions.

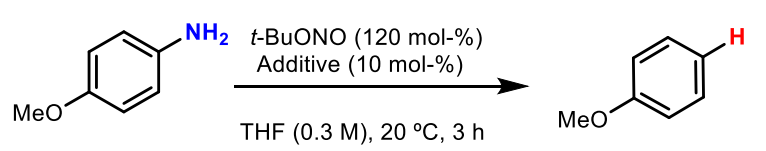

p-1a

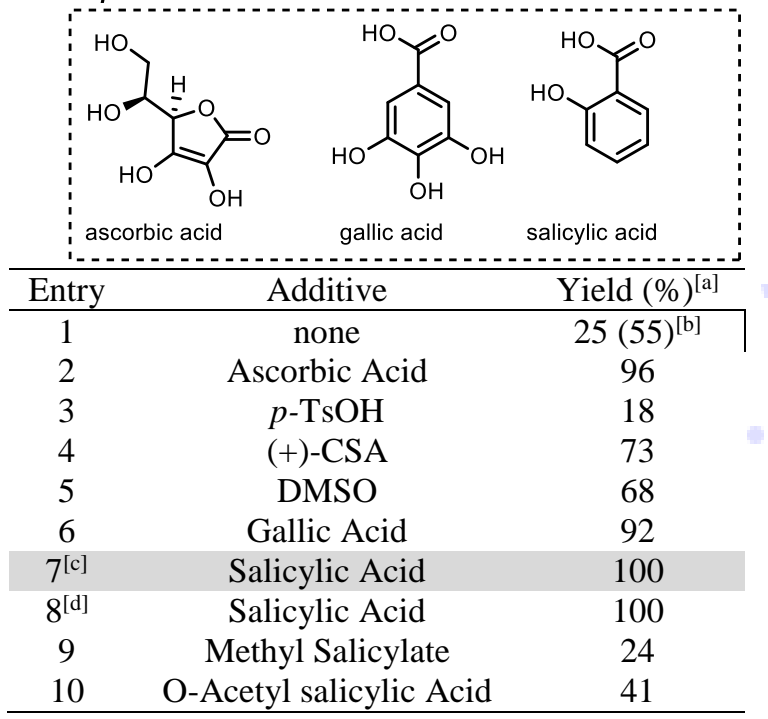

[a] Yield determined by GC with phenanthrene as the internal standard in $0.3 \mathrm{mmol}-\mathrm{scale}$ reactions.

${ }^{[b]}$ At THF reflux.

[c] Using 1:1 THF/ $\mathrm{H}_{2} \mathrm{O}$ as solvent, $50 \%$ yield of $2 \mathbf{a}$ was obtained.

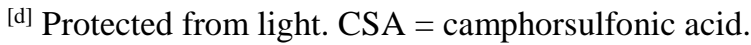

functionalities was tolerated, including ethers, esters, ketones, halogens, nitro, nitriles, alkyl, aryl, and trifluoromethyl. Remarkably, free carboxyl and hydroxyl groups at the para- position were also found to be compatible with this procedure (products $\mathbf{2 b}$ and $2 \mathbf{c}$ ). In other related methods, anilines bearing free hydroxyl groups afforded the corresponding deaminated products in very low yields, ${ }^{[10,12]}$ or did not react at all; ${ }^{[8]}$ this behavior could be likely due to azo coupling or other side reactions based on the nucleophilicity of the $\mathrm{OH}$ group. In contrast, the hydroxyl group at the ortho- position completely inhibited the reaction with our developed protocol. We speculated that the nitrosation step could be more difficult for this substrate, where an intramolecular hydrogen-bond might protect the amino group from the reaction with electrophiles. Despite iodine transfer is a well-known process in aryl radical chemistry, ${ }^{[24]}$ iodine-bearing anilines afforded the corresponding products in moderate-to-good yields [2h (from $o-, m$ - and $p$-iodoaniline) and $\mathbf{2 u}$ ]. This results suggest that if aryl radicals are involved, the hydrogen abstraction from THF should be faster than the iodine transfer. The protocol was also examined with different heteroaromatic amines to produce the heterocycles $\mathbf{2 p}, \mathbf{2 q}$, and $\mathbf{2 t}$ in moderate yields. Pyrimidine (2r) was also obtained, but in a lower yield, presumably because of the high electrophilicity of the intermediate diazonium ion. Moreover, the reaction was scale up to $5 \mathrm{mmol}$ for some substrates, 
Table 2. Substrate scope of aromatic amines. ${ }^{[a]}$

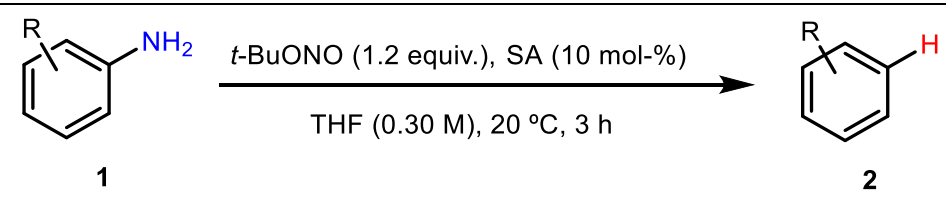<smiles>COc1ccccc1</smiles>

2a: $100 \%$<smiles>Brc1ccccc1</smiles>

2g: $70 \%$<smiles>COC(=O)c1ccccc1</smiles>

2d: $70 \%{ }^{[b]}$<smiles>Pc1ccccc1</smiles>

2k: $84 \%^{[c]}$<smiles>Clc1cccc2ccccc12</smiles><smiles>Oc1ccccc1</smiles>

2b: $45 \%$<smiles>Ic1ccccc1</smiles>

2h: $45 \%$<smiles>CC(=O)c1ccccc1</smiles><smiles>N#Cc1ccccc1</smiles>

2I: $69 \%$<smiles>O=C(O)c1ccccc1</smiles>

2c: $60 \%$<smiles>O=[N+]([O-])c1ccccc1</smiles>

2i: $69 \%$<smiles>Cc1ccccc1</smiles>

2m: $74 \%$<smiles>O=[N+]([O-])c1ccccc1</smiles>

2i: $60 \%$<smiles>CC(=O)c1ccccc1</smiles>

2d: $59 \%$<smiles>COc1ccccc1</smiles>

2a: $63 \%$<smiles>Clc1ccccc1</smiles>

2f: $100 \%$<smiles>FC(F)(F)c1ccccc1</smiles>

2n: $75 \%$<smiles>CC(=O)c1ccccc1</smiles>

2e: $60 \%$<smiles>Oc1ccccc1</smiles>

2b: $0 \%$<smiles>Brc1ccccc1</smiles>

2g: $77 \%$<smiles>Clc1ccccc1</smiles>

2f: $75 \%$<smiles>Clc1ccccc1</smiles>

2f: $96 \%$<smiles>[R]#[W]c1nc2ccccc2[nH]1</smiles><smiles>Ic1nc2ccccc2s1</smiles>

2q: $58 \%$<smiles>c1cnccn1</smiles>

$2 r: 22 \%$<smiles>Clc1cccc(-c2ccccc2)c1</smiles>

2s: $(93 \%)$<smiles>COC(=O)c1cccs1</smiles>

2t: $(50 \%)$<smiles>O=C(c1ccccc1)c1ccccc1</smiles>

2j: $84 \%$<smiles>Ic1ccccc1</smiles>

2h: $60 \%$<smiles>Ic1ccccc1</smiles>

2h: $42 \%$

[a] GC yields vs. phenanthrene from $0.3 \mathrm{mmol}$ of $\mathbf{1}$ (in parentheses the yields of isolated pure products from $5 \mathrm{mmol}$ of $\mathbf{1}$ ). The $\mathrm{H}$ atom in red indicates the original position of the amino group in the starting amine.

[b] $73 \%$ yield of isolated pure product for a 5 mmol-scale reaction.

[c] $82 \%$ yield of isolated pure product for a 5 mmol-scale reaction.

giving rise to the pure products $(2 \mathbf{d}, 2 \mathbf{2}, 2 \mathbf{p}, \mathbf{2 s}, 2 \mathrm{t}$ and $\mathbf{2 u}$ ) in good-to-excellent isolated yields. It is also noteworthy that significantly higher yields were obtained for some substrates which were reported to react under refluxing THF without any catalyst (e.g. $p-\mathbf{1 b}, o-1 h$ and $p-1 k) .{ }^{[10]}$

In order to test the applicability of this protocol at a larger preparative scale, we performed the hydrodeamination with $10 \mathrm{mmol}$ of the substrate $\mathbf{1 v}$. Following the standard procedure in a gram-scale, product $\mathbf{2 v}$ was obtained in good yield after purification (Scheme 2). We must highlight that aniline $1 \mathbf{v}$ was prepared by nitration from $p$-anisidine (in three steps) following a reported procedure, ${ }^{[25]}$ the hydrodeamination of which also demonstrates the potential of this method to use the amino functionality as a traceless directing group in $\mathrm{S}_{\mathrm{E}} \mathrm{Ar}$.

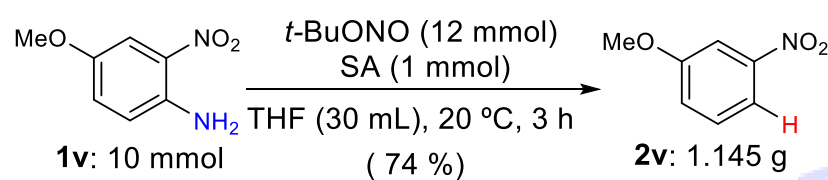

Scheme 2. Gram-scale hydrodeamination reaction.

We next examined the feasibility of this protocol for the deuterodeamination of aromatic amines using $\left[\mathrm{D}_{8}\right]$-THF as solvent. In this case, the standard procedure was slightly modified to utilize lower amounts of the deuterated reagent and the reactions were run in $0.5 \mathrm{M}$ solutions for $2 \mathrm{~h}$. As shown in Table 3, six anilines were selected for this study from the previous examined substrates (Table 2) taking 
into account their diverse functionalization and the low volatility of the products. In all cases, the incorporation of deuterium was excellent, obtaining compounds with $\geq 97: 3 \mathrm{D} / \mathrm{H}$ ratio, according to ${ }^{1} \mathrm{H}$ NMR. It is worth mentioning that in many reported arene deuteration protocols, other competitive $\mathrm{H}-$ transfer processes take place efficiently, resulting in lower isotope incorporation. ${ }^{[26]}$ Although the yields obtained for the deuterated products were uniformly slightly lower than those for the hydrogenated counterparts, reasonable yields for isolated pure deuterated compounds were obtained $(42-81 \%)$ in only $2 \mathrm{~h}$ at $20^{\circ} \mathrm{C}$.

Table 3. Deuterodeamination reaction with $\left[\mathrm{D}_{8}\right]-\mathrm{THF}{ }^{[\mathrm{a}]}$

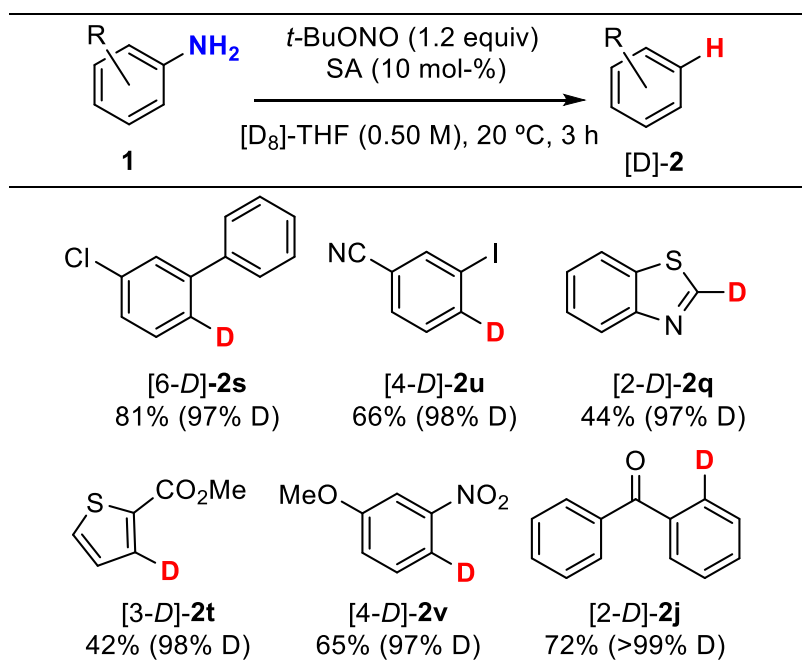

[a] Yields are reported for isolated pure products from 0.3 mmol of $\mathbf{1}$. The percentages of deuteration were determined by ${ }^{1} \mathrm{H}-\mathrm{NMR}$.

We performed some control experiments to gain an insight into the reaction pathway. As shown in Scheme 3a, we were able to recover most of the salicylic acid used as catalyst (GC-MS determination) by aqueous workup, once the hydrodeamination of 1a was finished. In order to show the intermediacy of aryl radicals, we performed the deamination of $\boldsymbol{p}$-1i in $\mathrm{CH}_{3} \mathrm{CN}$ (to minimize $\mathrm{H}$-abstraction) using 2,2,6,6tetramethylpiperidinyl-1-oxy radical (TEMPO) as a radical trap (Scheme 3b); ${ }^{[27]}$ adduct 3 was isolated in $56 \%$ yield after purification. Additionally, when a solution of the substrate $\boldsymbol{p}$-1g and 2-iodoacetic acid in $\mathrm{CH}_{3} \mathrm{CN}$ was treated with salicylic acid (10 mol-\%) and $t$-BuONO, 4-bromoiodobenzene was isolated as a pure solid in 52\% yield (Scheme 3c), suggesting the formation of 4-bromophenyl radical. ${ }^{[28]}$ Furthermore, when equimolar amounts of $\mathrm{THF} /\left[\mathrm{D}_{8}\right]$-THF were used under our standard conditions for the hydrodeamination of $\mathbf{1 v}$, a $27 \%$ of deuterium incorporation was observed in product $2 \mathbf{v}$ at the initial stage of the reaction (Scheme 3d). The large KIE obtained $\left(k_{\mathrm{H}} / k_{\mathrm{D}}=2.70\right)$ suggests that $\mathrm{H}$ abstraction from THF is the rate-determining step of the reaction.
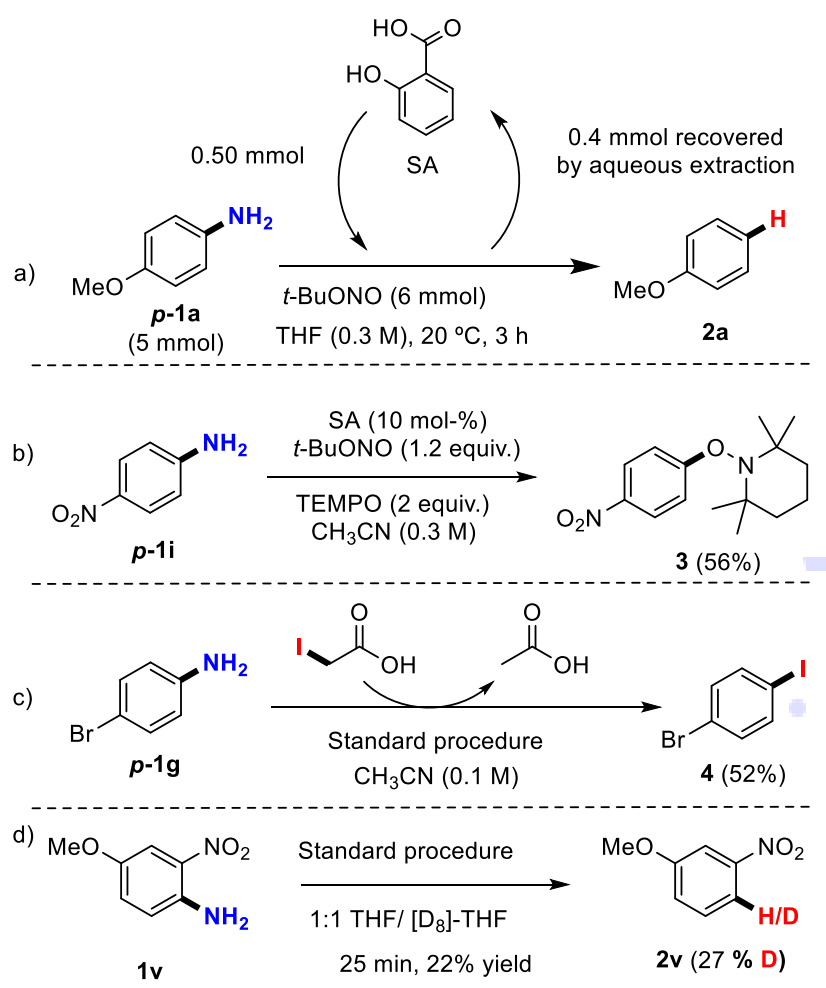

Scheme 3. Control experiments for mechanistic studies.

Given the above mentioned control experiments and inspired by mechanistic investigations previously reported, ${ }^{[17-21]}$ we have proposed a plausible mechanism for this reaction (Scheme 4). The fact that $O$-acetyl salicylic acid has a moderate positive impact on the reaction, while methyl salicylate does not act as catalyst suggested that the carboxylate is directly involved in the reaction. Considering the reported redox potentials for the reduction of diazonium salts $\left(\mathrm{E}_{\text {red }} \approx 0 \mathrm{~V} \text { vs } \mathrm{Ag} / \mathrm{AgCl}\right)^{[29]}$ and oxidation of salicylates $\left(\mathrm{E}_{\mathrm{red}} \approx+1.1 \mathrm{~V}\right.$ vs $\left.\mathrm{Ag} / \mathrm{AgCl}\right),{ }^{[30]}$ a single electron transfer (SET) between these species seems unreasonable as the initiation step because it is an endergonic reaction $(\Delta \mathrm{E} \approx-1 \mathrm{~V})$. Therefore, we propose that the in-situ formed diazonium salt $\mathbf{I}$ is protonated by salicylic acid and undergoes a nucleophilic addition of salicylate through the carboxy group. The aryl diazobenzoate intermediate II could easily decompose to generate $\mathrm{N}_{2},{ }^{\left[{ }^{[1]}\right.}$ the aryl radical (trapped with TEMPO and with iodoacetic acid) and salicyloyl radical (likely stabilized by an intramolecular $\mathrm{H}$-bond). While further experiments are required to support this proposed mechanism, we have also confirmed that the reaction is not promoted by visible-light (CFL lamps; Table 1 , entry 8 ) and occurs under very mild thermal activation $\left(20^{\circ} \mathrm{C}\right)$. The aryl radical could rapidly abstract a hydrogen atom (HAT) from THF $\left(\mathrm{k} \sim 10^{6} \mathrm{M}^{-1} \mathrm{~s}^{-1} \text { at } 25^{\circ} \mathrm{C}\right)^{[32]}$ to form the product and the $\alpha$-tetrahydrofuranyl radical (IV). The reaction could be propagated through a radical-chain mechanism where the aryl diazonium salt is reduced by radical IV, regenerating the aryl radical and forming the oxoniun ion $\mathbf{V}$ which, eventually, would lead to volatile ketal or hemiketal 
by-products. ${ }^{[33]}$ The oxidation potential of potassium salicylate $\left(\mathrm{E}_{1 / 2}=+1.1 \mathrm{~V}\right.$ vs $\left.\mathrm{Ag} / \mathrm{AgCl}\right)$ is reported to be rather low compared with that of the parent potassium benzoate $\left(\mathrm{E}_{1 / 2}>1.5 \mathrm{~V}\right.$ vs $\left.\mathrm{Ag} / \mathrm{AgCl}\right){ }^{\left[{ }^{[29]}\right.}$ This suggests that the hydroxyl group at the ortho-position stabilizes radical III, probably by H-bond stabilization and a captodative effect of the carboxyl and hydroxyl groups. ${ }^{[34]}$ It seems reasonable that the turnover of the catalyst (which was isolated in native form after the reaction) could be produced by singleelectron reduction of III by radical IV.

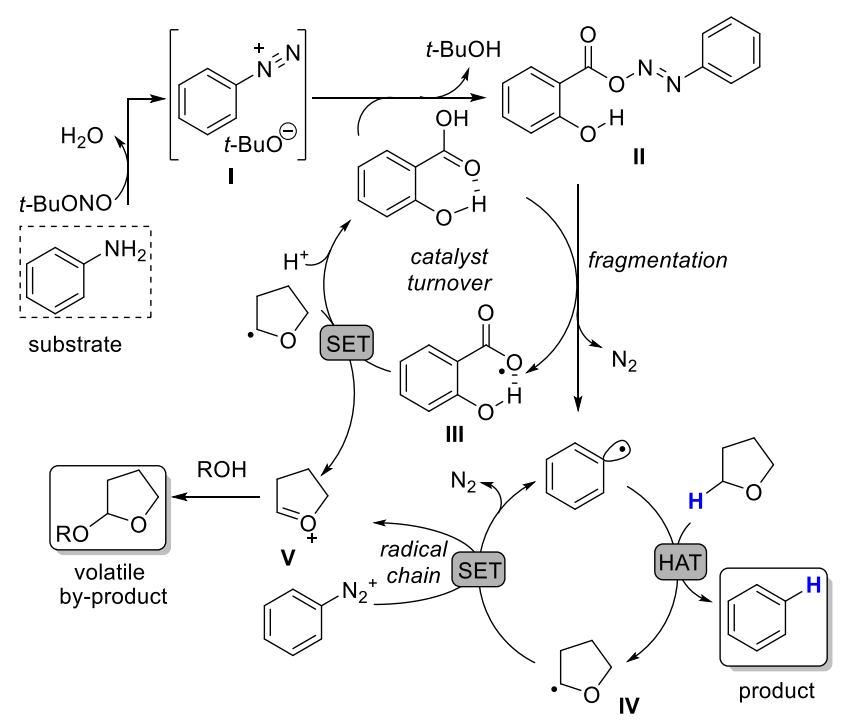

Scheme 4. Proposed reaction mechanism.

\section{Conclusion}

In summary, we have reported a convenient onepot methodology for the selective hydrodeamination of anilines and heteroaromatic amines using THF as the hydrogen source. The reaction is catalyzed by salicylic acid (10 mol-\%) and takes place at $20^{\circ} \mathrm{C}$ in 2-3 h, without any metal additive, stoichiometric reductant or light induction. Importantly, the reaction conditions are compatible with the presence of a variety of functional groups, irrespective of their electron-donating or -withdrawing character. Moreover, the method is easily scalable up to 10 mmol-scale. Remarkably, the use of commercial [D8]-THF allowed the selective deuterodeamination of aromatic amines with excellent isotopic purity of the products. Mechanistic studies revealed that aryl radicals are reaction intermediates and that the hydrogen transfer from THF is a rate-limiting step of the reaction. We hope that the use in this report of the underexploited salicylic acid as catalyst, to facilitate the formation of aryl radicals, will find future synthetic applications. We are currently working on new sustainable methods to expand the application of this concept.

\section{Experimental Section}

General Procedure for the hydrodeamination reaction (Table 2)

The corresponding aniline $(0.30 \mathrm{mmol})$ and the salicylic acid $(4.14 \mathrm{mg}, 0.03 \mathrm{mmol})$ were added to an oven dried Schlenck. The system was evacuated and filled with argon (three times) before dry THF $(1 \mathrm{~mL})$ was added, and the reaction mixture was stirred vigorously until a homogeneous solution was obtained (5 min aprox.). At this point, tert-butylnitrite $(47 \mu \mathrm{L}, 41.3 \mathrm{mg}, 0.36 \mathrm{mmol})$ was added (the solution turned orange after some minutes) and the stirring continued for $3 \mathrm{~h}$, keeping the temperature at $20{ }^{\circ} \mathrm{C}$ with a water bath. At this time, water was added $(2$ $\mathrm{mL})$ and the mixture was extracted with EtOAc $(3 \times 4 \mathrm{~mL})$. The organic layers were collected, dried over anhydrous $\mathrm{MgSO}_{4}$ and filtered. To this solution was added phenanthrene $(53.4 \mathrm{mg}, 0.3 \mathrm{mmol}$ ) as the internal standard (IS). An aliquot of this solution was injected into a GC apparatus to determine the reaction yield. Substrates $\boldsymbol{o - 1 d}$ $\boldsymbol{o}-\mathbf{1 k}, \mathbf{1 p}, \mathbf{1 s}, \mathbf{1 t}$, and $\mathbf{1 u}$ were subjected to this procedure at 5-mmol scale and $\mathbf{1 v}$ at 10 -mmol scale, and the corresponding compounds $\mathbf{2}$ were isolated in pure form after column chromatography to determine the yields. ${ }^{[35]}$

\section{General Procedure for the deuterodeamination} reaction (Table 3)

Following the aforementioned general procedure for selected anilines $(\boldsymbol{o}-\mathbf{1} \mathbf{j}, \mathbf{1 q}, \mathbf{1 s}, \mathbf{1 t}, \mathbf{1} \mathbf{u}$ and $\mathbf{1 v})$, but using dry $\left[\mathrm{D}_{8}\right]$-THF $(0.50 \mathrm{M})$, the corresponding [D]-2 compounds were obtained in pure form after column chromatography. ${ }^{[36]}$

\section{Supporting Information}

Details for experimental procedures, determination of yields by gas chromatography (Tables S1, S2 and S3), purification and characterization data of the isolated compounds are included. Some mechanistic studies, and NMR spectra $\left({ }^{1} \mathrm{H}-\right.$ and $\left.{ }^{13} \mathrm{C}-\mathrm{NMR}\right)$ of the pure isolated compounds are also included.

\section{Acknowledgements}

We thank the Ministerio de Economia y Competitividad (CTQ2015-66624-P) and the University of Alicante (VIGROB173) for financial support.

\section{References}

[1] N. Kornblum, Org. React., 1944, 2, 262.

[2] a) H. T. Clarke, E. R. Taylor, Org. Synth. Coll. 1941, I, 415; b) A. H. Blatt, Org. Synth. Coll., 1950, II, 592.

[3] a) N. Kornblum, G. D. Cooper, J. E. Taylor, J. Am. Chem. Soc. 1950, 72, 3021; b) N. Kornblum, A. E. Kelley, G. D. Cooper, J. Am. Chem. Soc. 1952, 74, 3074.

[4] T. Itoh, K. Nagata, Y. Matsuya, M. Miyazaki, A. Ohsawa, J. Org. Chem. 1997, 62, 3582.

[5] K. H. Park, Y. H. Cho, E. J. Jang, Bull. Korean Chem. Soc. 1996, 17, 179.

[6] F. W. Wassmundt, W. F. Kiesman, J. Org. Chem. 1995, $60,1713$. 
[7] M. Lormmann, S. Dahen, S. Bräse, Tetrahedron Lett. 2000, 41, 3813.

[8] M. Majek, F. Filace, A. J. von Wangelin, Chem. Eur. J. 2015, 21, 4518.

[9] N. Kornblum, D. C. Iffland, J. Am. Chem. Soc. 1949, $71,2137$.

[10] J. I. G. Cadogan, G. A. Molina, J. Chem. Soc. Perkin Trans I, 1973, 541.

[11] M. P. Doyle, J. F. Dellaria, B. Siegfried, S. W. Bishop, J. Org. Chem. 1977, 42, 3494.

[12] O. J. Geoffroy, T. A. Morinelli, G. P. Meier, Tetrahedron Lett. 2001, 42, 5367.

[13] K. Burglova, S. Okorochenkov, J. Hlavac, Org. Lett. 2016, 18, 3342.

[14] E. M. Simmons, J. F. Hartwig, Angew. Chem. Int. Ed. 2012, 51, 3066 .

[15] A. Katsnelson, Nat. Med. 2013, 19, 656.

[16] D. Prat, A. Wells, J. Hayler, H. Sneddon, C. R. McElroy, S. Abou-Shehada, P. J. Dunn, Green Chem. 2016, 18, 288.

[17] F. P. Crisóstomo, T. Martín, R. Carrillo, Angew. Chem. Int. Ed. 2014, 53, 2181.

[18] M. D. Perretti, D. M. Monzón, F. P. Crisóstomo, V. S. Martín, R. Carrillo, Chem. Commun. 2016, 52, 9036.

[19] M.-j. Bu, G.-p. Lu, C. Cai, Synlett 2015, 26, 1841.

[20] M.-j. Bu, G.-p. Lu, C. Cai, Org. Chem. Front. 2016, 3, 630.

[21] F.-Q. Huang, G.-X. Zhou, X. Dong, L. W. Qi, B. Zhang, Asian J. Org. Chem. 2016, 5, 192.

[22] a) T. Kauffmann, H. O. Friestad, H. Henkler, Liebigs Ann. Chem. 1960, 634, 64; b) E. Müller, H. Haiss, Chem. Ber. 1962, 95, 570; c) E. Müller, H. Haiss, Chem. Ber. 1962, 95, 1255.

[23] D. Cantillo, C. Mateos, J. A. Rincon, O. de Frutos, C. O. Kappe, Chem. Eur. J. 2015, 21, 12894.

[24] a) J. F. Bunnet, C. C. Waser, J. Am. Chem. Soc. 1966, 88, 5534; b) D. L. Brydon, J. I. G. Cadogen, J. Chem. Soc. C. 1968, 819; c) T. J. Broxton, J. F. Bunnett, C. H. Paik, J. Org. Chem. 1977, 42, 643.

[25] P. E. Fanta, D. S. Tarbell, Org. Synth. 1945, 25, 78.
[26] For selected examples, see: a) F. W. Wassundt, W. F. Kiesman, J. Labelled Compd. Radiopharm. 1995, 36, 281; b) T. Mutsumi, H. Iwata, K. Maruhashi, Y. Monguchi, H. Sajiki, Tetrahedron 2011, 67, 1158; c) M. Rudzki, A. Alcalde-Aragonés, W. I. Dzik, N. Rodríguez, L. J. Gooßen, Synthesis 2012, 184; d) R. Grainger, A. Nikmal, J. Cornella, I. Larrosa, Org. Biomol. Chem. 2012, 10, 3172; e) Ma, G. Villa, P. S. Thuy-Boun, A. Homs, J.-Q. Yu, Angew.Chem. Int. Ed. 2014, 53,734.

[27] Under the standard conditions, but using $\mathrm{CH}_{3} \mathrm{CN}$ as solvent, only $21 \%$ of $\mathbf{2 i}$ was obtained.

[28] a) F. W. Wassmundt, W. F. Kiesman, J. Org. Chem. 1995, 60, 1713; b) F. W. Wassmundt, W. F. Kiesman, J. Org. Chem. 1997, 62, 8304.

[29] H.-H. Yang, R. L. McCreery, Anal. Chem. 1999, 71, 4081.

[30] J. Colucci, V. Montalbo, R. Hernandez, C. Pouullet, Electrochim. Acta 1999, 44, 2507.

[31] It is known that acyloxydiazoaryls decompose easily to generate aryl radicals. For selected examples, see: a) R. Huisgen, G. Horeld, Liebigs Ann. Chem 1949, 562, 137; b) C. Rüchardt, B. Freudenberg, Tetrahedron Lett. 1964, 5, 3623; c) J. I. G. Cadogan, Acc. Chem. Res. 1971, 4, 186. However, we were unable to isolate intermediate II in pure form and other pathways for the salicylic acid catalyzed generation of aryl radicals cannot be ruled out.

[32] J. Fossy, D. Lefort and J. Sorba, Free Radicals in Organic Chemistry, John Wiley \& Sons, 1995, p 289.

[33] 2-Hydroxytetrahydrofuran (GC-MS included on page S17 of the Supporting Information) has been detected by GC-MS in the formation of $\mathbf{2 a}$ under the standard conditions. The formation of 2-tertbutoxytetrahydrofuran, and its subsequent fast transformation under the GC-MS conditions, cannot be ruled out.

[34] A similar explanation was proposed for the special stabilization of the galloyl radical. See reference 18 .

[35] More experimental details are included in the Supporting Information file (pages S7-S11).

[36] More experimental details are included in the Supporting Information file (pages S12-S15). 


\section{UPDATE}

\section{Salicylic Acid-Catalyzed One-Pot}

Hydrodeamination of Anilines by tert-Butyl Nitrite in Tetrahydrofuran

Adv. Synth. Catal. Year, Volume, Page - Page

Diego Felipe-Blanco, Francisco Alonso, Jose C. Gonzalez-Gomez*

$$
\begin{aligned}
& \mathrm{Ar}-\mathrm{NH}_{2} \stackrel{t \text {-BuONO (1.2 equiv) }}{\longrightarrow}[\mathrm{Ar}] \longrightarrow \mathrm{Ar}-\mathrm{H}
\end{aligned}
$$

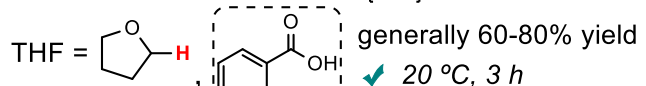

$$
\begin{aligned}
& 31 \text { examples } \\
& \checkmark \text { high tolerance } 110 \text { mol-\%,' } \checkmark \text { deuteration with THF- } D_{8} \\
& \text { towards functional groups }
\end{aligned}
$$

